\title{
Rapid Evaluation of Salmonella pullorum Contamination in Chicken Based on a Portable Amperometric Sensor
}

\author{
Guoyan Liu1, Chunyan Chai ${ }^{1 *}$ and Bing Yao
}

${ }^{1}$ Key Laboratory of Shanghai Veterinary Biotech, Shanghai, China

${ }^{2}$ School of Agriculture \& Biology, Shanghai Jiaotong University, Shanghai, 200240, China

\begin{abstract}
In this study, anti-Salmonella polyclonal antibodies immobilized on cellulose nitrate membrane were used to capture Salmonella pullorum (S. pullorum) in biological samples. The rapid evaluation of S. pullorum contamination was based on the analysis of the activities of catalase, a biomarker of this bacterium. After a screen printed electrode (SPE) modified with multi-wall carbon nanotubes (MWCN)-chitosan-peroxidase was connected to a portable selfmade amperometric sensor, the determination of $S$. pullorum contamination was carried out by adding the reaction product, which was obtained from the hydrogen peroxide dismutation catalyzed by the bacterial catalase, to the reacting area of the SPEs. A working potential of $0.55 \mathrm{~V}$ was applied in the sensing system and the current value displayed on the amperometric sensor was used as the detection signal. This method allowed the quantification of S. pullorum with the detection limit of $100 \mathrm{cfu} \mathrm{mL}^{-1}$ in culture media and chicken samples. The stability, reproducibility and sensitivity of the modified SPE were also investigated. Moreover, successive analysis was conveniently accomplished by replacing the one-off SPE. This portable sensing system is a rapid, cost-effective and straightforward approach for screening S. pullorum contamination in food samples.
\end{abstract}

Keywords: Salmonella pullorum; Portable amperometric sensor; Catalase; Screen printed electrodes

\section{Introduction}

Salmonella, one of the most frequently reported causes of food-borne illness in the world, is widely distributed in animals and environment [1-3]. Under the condition that the appliance or the environment is contaminated by the salmonella from the feces of livestock, the bacteria can be easily spread on the chain of slaughtering, transportation, processing, storage and selling. Under proper conditions, the salmonella has the ability of proliferating very quickly and food-borne toxicosis would be caused after the amount of the bacteria accumulates to certain level, imperiling the health of victims, even leading to human deaths [4-6]. Many studies have been reported on the development of new methodologies for the detection and identification of Salmonella typhimurium, one of the vital food-borne pathogens most likely to be found in slaughtered livestock and poultry [7-15]. However, the impairments of human health and economy caused by other serotypes of Salmonella cannot be neglected. S. pullorum and S. gallinarum are the major bacterial pathogens causing significant economic losses to the poultry industry in many parts of the world [16-18]. In addition, the presence of $S$. pullorum in food sample is still a public concern in China when the food quality and safety are considered. Therefore, the quantification of both pathogenic and spoilage microorganism in food samples is an essential and necessary practice. Conventional methods for the analysis of bacterial contamination were based on the isolation of the target microorganism on specific culture media and the count of viable bacterial cells. However, these methods require 3-4 days for presumptive results and 5-7days for confirmation [19]. Up to now, several rapid approaches and alternative methods have been developed for the detection of Salmonella, including polymerase chain reaction [20-24], immunoassay [25-28], bioluminescence [29,30] and impedimetry [31-33]. The drawbacks of these applications are the complexity and limited applicability for on-site detection. In recent years, biosensors for detection of food-borne Salmonella have been developed. They include piezoelectric biosensor [34,35], compact fiberoptic evanescent wave sensing system [36], immuno-optical sensor $[37,38]$ and immune electrochemical sensor [39-42]. However, one or some of the disadvantages were indicated in these methods including high detection limit, low regeneration of the antibody-coated surface for multiple uses and high cost of the instrument and materials.

In this study, we designed and fabricated a novel biosensor for fast detection of $S$. pullorum contamination in food samples by using MWCN-chitosan-peroxidase modified SPEs and anti-Salmonella polyclonal antibodies immobilized on cellulose nitrate membrane. We hypothesized that these techniques are very helpful to improve the sensitivity and selectivity of this sensing system. It is hoped that, in practical on-site use, the determination of $S$. pullorum can be easily carried out after a modified SPE is connected to a portable self-made amperometric sensor and successive analysis can be conveniently accomplished by replacing the one-off SPE.

\section{Materials and Methods}

\section{Materials and apparatus}

Wild-type S. pullorum was isolated and generously provided by Zuli Wu, professor of Shanghai Zoonosis Key Laboratory (Shanghai, China). Horseradish peroxidase (HRP) (EC 1.11.1.7, type I, activity $148 \mathrm{U} \mathrm{mg}^{-1}$ of solid), bovine serum albumin (BSA), N, N, N', N'tetramethylbenzidine dihydrochloride (TMB) and ferrocene were purchased from Sigma (St. Louis, MO, USA). 25\% Nafion was obtained from Nanjing Huiyu Energy Resource Co. Limited (Nanjing, China). Goat anti-Salmonella pullorum polyclonal antibody was provided by

${ }^{*}$ Corresponding author: Chunyan Chai, Key Laboratory of Shanghai Veterinary Biotech, Shanghai, China, Tel: 8621-34206927; Fax: 8621-34205582; E-mail: cychai88@hotmail.com

Received May 15, 2013; Accepted June 22, 2013; Published June 24, 2013

Citation: Liu G, Chai C, Yao B (2013) Rapid Evaluation of Salmonella pullorum Contamination in Chicken Based on a Portable Amperometric Sensor. J Biosens Bioelectron 4: 137. doi:10.4172/2155-6210.1000137

Copyright: (c) 2013 Liu G, et al. This is an open-access article distributed under the terms of the Creative Commons Attribution License, which permits unrestricted use, distribution, and reproduction in any medium, provided the original author and source are credited. 
Ningbo Tianrun Biopharmaceutical Co. Limited (Ningbo, China). 30\% $\mathrm{H}_{2} \mathrm{O}_{2}$, acetic acid, water-soluble Chitosan and 25\% (wt.) glutaraldehyde were obtained from Shanghai Reagent Corporation (China). $\mathrm{H}_{2} \mathrm{O}_{2}$ stock solution was standardized using the conventional titration method and serially diluted $\mathrm{H}_{2} \mathrm{O}_{2}$ working solutions were prepared in sterile distilled water. MWCN (99.9\%, - $\mathrm{COOH}, 20-30 \mathrm{~nm})$ was purchased from Chengdu Organic Chemicals Co. Limited of Chinese Academy of Science (Chengdu, China). Other reagents, including nitric acid, acetate acid and phosphate, were analytical grade and purchased from Lingfeng Reagent Company (Shanghai, China). Skimmed milk powder was supplied by Shanghai Bright Dairy Corporation (Shanghai, China). Cellulose nitrate membrane $(0.22 \mu \mathrm{m})$ was purchased from Millipore (USA). FD-1 vacuum freezing dryer was provided by Tianfeng Instrument Company (Shanghai, China). DUA $\hat{A}^{\circledR} 800 \mathrm{UV} /$ visible spectrophotometer was obtained from Bechman Coulter, Inc. (USA). CHI 660C Electrochemistry Working Station was provided by Shanghai CHI Instrument Co. Limited (Shanghai, China).

\section{Modification of SPE by MWCN-chitosan-peroxidase}

The SPEs used in this study were kindly provided by Shanghai Bioscan Inc (Shanghai, China). The shape of individual SPE was rectangular with the size of $7 \mathrm{~mm} \times 33 \mathrm{~mm}$. Two parallel conductive rails were connected with two terminal posts and two electrodes areas used as working electrode (size, $2 \mathrm{~mm} \times 3 \mathrm{~mm}$ ) and counter electrode (size, $2 \mathrm{~mm} \times 3 \mathrm{~mm}$ ), respectively. The first layer of electric-conductive silver paste was printed on a polyvinyl chloride board based on the designed structure shown in Figure 1. The second layer was electric-conductive carbon paste which was printed exactly on the same area covered by the silver paste. An insulation layer was coated on the proper area the SPE, exposing the working area and terminal post for insertion into the slot of a portable amperometric sensor.

The new SPEs were pre-treated in $20 \% \mathrm{H}_{2} \mathrm{SO}_{4}$ solution containing $5 \% \mathrm{H}_{2} \mathrm{O}_{2}$, followed by washing ultrasonically in ethanol and distilled water, respectively. $0.5 \mathrm{mg}$ of the untreated MWCNs was added to $5 \mathrm{~mL}$ of nitric acid (wt. 65\%) and the mixture was submitted to sonication for $2 \mathrm{~h}$ to obtain a relative stable suspension. $4 \mu \mathrm{L}$ of the black suspension of MWCNs was casted onto the working area of the SPEs respectively and dried in an over at $45^{\circ} \mathrm{C}$ to remove the acid, followed by washing in distilled water and drying at room temperature for the next modification. $100 \mathrm{mg}$ of water-soluble chitosan was dissolved in $10 \mathrm{~mL}$ acetic acid (wt. 1\%) and $4 \mu \mathrm{L}$ of the mixture was added respectively to the working

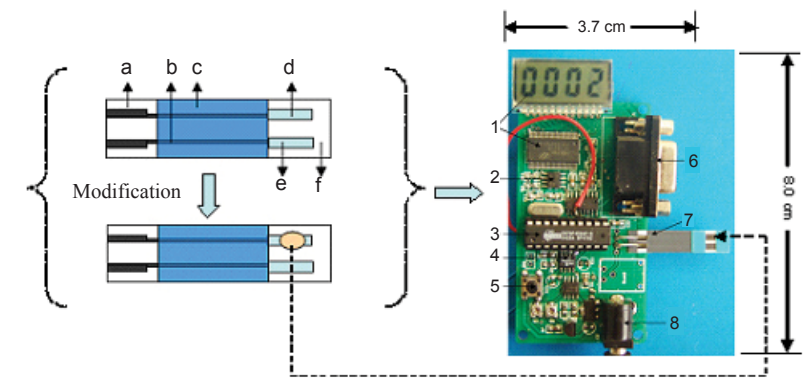

Figure 1: Schematic diagram of the SPE and components of the hardware of the amperometric sensor. The schematic structure of SPE consisted of following parts: (a) terminal post, (b) electric conductive rail, (c) insulation layer, (d) working electrode, (e) counter electrode and (f) polyvinyl chloride board. The hardware components of the amperometric sensor: (1) liquid crystal display and HT1621 driving chip, (2) MCP3201 A/D converter, (3) EM78P458 single-chip microcomputer, (4) operational amplifier, (5) function key, (6) data-interface, (7) SPE slot and (8) battery (output, $6 \mathrm{~V}$ ). area of the SPEs modified with MWCNs described above. Then the SPEs modified with MWCN-chitosan was washed in distilled water and dried at room temperature again. The last step of modification was performed by adding $4 \mu \mathrm{L}$ of peroxidase-BSA solution to the working area of SPEs modified with MWCN-chitosan. This enzymatic solution contained $1 \mathrm{mg} \mathrm{mL}^{-1}$ of peroxidase, $0.25 \%$ (wt.) of BSA and $0.025 \%$ (wt.) of glutaraldehyde. The MWCN-chitosan-peroxidase modified SPEs were allowed to stand at $4^{\circ} \mathrm{C}$ overnight and washed by $0.01 \mathrm{M}$ PBS ( $\mathrm{pH}$ 7.2). After the modified SPEs were dried by lyophilization, they were sealed in a plastic bag and stored at $4^{\circ} \mathrm{C}$ for future use.

\section{Design and assembling of portable amperometric sensor}

The design and assembling of the portable amperometric sensor was accomplished with the help of the postgraduates in Dr. Jingqi Yuan's laboratory (School of Electronic, Information and Electrical Engineering, Shanghai Jiaotong University, Shanghai, China). The hardware structure of the sensor mainly consisted of the following parts: (1) liquid crystal display and HT1621 driving chip (Holtek Electronic Company, Taiwan), (2) MCP3201 A/D converter (Microchip Company, USA) (3) EM78P458 single-chip microcomputer (Elong Electronic Company, Taiwan), (4) operational amplifier, (5) function key, (6) datainterface, (7) SPE slot, (8) battery (output, $6 \mathrm{~V}$ ) and other peripheral equipments. The software of this sensor was developed based on the WicePlus translator editor (Elong Electronic Company, Taiwan).

\section{Bacteria culture and plating method}

The Regulations of Operation (2003) established in our laboratory were strictly followed for safety considerations. Wild-type $S$. pullorum was grown overnight at $37^{\circ} \mathrm{C}$ on a nutrient agar containing Salmonella-Shigella (S.S.) culture media to obtain a pure culture of the microorganism. Round translucent small colonies were observed on the agar. Gram staining showed that this bacterium was Gram-negative short bacillus without capsule and spore. Biochemical identification confirmed that $S$. pullorum was catalase-positive microorganism. Two or three representative colonies were transferred aseptically to 10 $\mathrm{mL}$ of the nutrient broth. The $S$. pullorum cultures were incubated at $37^{\circ} \mathrm{C}$ with aeration by shaking. After the growing stationary phase was reached, the enumeration of the colonies was carried out by inoculating the serially diluted (10-fold steps) bacterial cultures to the Luria broth agar plates and incubating overnight at $37^{\circ} \mathrm{C}$. To establish a calibration graph for relating the optical density value with viable count in serial dilutions of the bacterial cultures, serial dilutions (5-10-fold depending on the requirements of the experimental protocol) were prepared in the nutrient broth and the optical density of each suspension was measured on a DUÂ $\hat{A}^{\circledR} 800 \mathrm{UV} /$ visible spectrophotometer at a wavelength of $450 \mathrm{~nm}$.

\section{Immobilization of anti-Salmonella polyclonal antibodies on cellulose nitrate membrane}

Round chips of cellulose nitrate membrane were made according to the size of the wells (diameter, $15 \mathrm{~mm}$ ) in the plastic tissue culture plate. The chips were put respectively on the bottom of 24 wells of the plate. Goat anti-Salmonella polyclonal antibodies were diluted by 100 folds using 0.01 M PBS (pH7.2). $300 \mu \mathrm{L}$ of the antibody solution was added to the wells respectively and incubated at $37^{\circ} \mathrm{C}$ for $1 \mathrm{~h}$, followed by washing with PBS two times. The unspecific sites on the cellulose nitrate membrane were blocked by the treatment with PBS solution containing $3 \%$ skimmed milk powder at $37^{\circ} \mathrm{C}$ for $20 \mathrm{~min}$, followed by washing the plate in PBS three times. After the drying procedure by lyophilization, the plate was sealed in polyethylene bag and stored at $4^{\circ} \mathrm{C}$ for further use. 


\section{Protocols for the detection of S. pullorum on the portable amperometric sensor}

Prior to the determination of $S$. pullorum on the portable amperometric sensor, the culture plate from the previous step 2.5. was retrieved from the polyethylene bag and $0.5 \mathrm{~mL}$ of bacterial samples was transferred into each of the 24 plate wells respectively, followed by incubating the plate on a shaking machine at room temperature for 20 min. After the plate was washed in PBS $(0.01 \mathrm{M}, \mathrm{pH} 7.2)$ containing $0.01 \%$ Tween-20 for three times, $0.5 \mathrm{~mL}$ of $0.1 \mathrm{M}$ acetate buffer $(\mathrm{pH} 6.0)$ containing $100 \mu \mathrm{M} \mathrm{H}_{2} \mathrm{O}_{2}$ and $20 \mathrm{mM} \mathrm{TMB}$ was added into one of the plate wells. The mixture was allowed to react for a fixed time (8 $\mathrm{min})$. After a SPE modified with MWCN-chitosan-peroxidase was connected to a portable self-made amperometric sensor, $15 \mu \mathrm{L}$ of the mixture from the previous step was added onto the reacting area of the modified SPE. A working potential of $0.55 \mathrm{~V}$ was applied in the sensing system and the currents were recorded at appropriate time (20 seconds) as the sensor signals. The successive detections of $S$. pullorum in different samples were easily performed by replacing the one-off modified SPE with a new one.

\section{Determination of $S$. pullorum in chicken samples}

Thirty chicken samples were collected randomly from three outdoor food markets in Shanghai. All the samples were immediately subjected to the detection of S. pullorum on the portable amperometric sensor under the optimized methods described in Section 3. Briefly, one gram of chicken from each sample was minced in a sterile glass homogenizer. $5 \mathrm{~mL}$ of PBS was used to remove the homogenate from the homogenizer. Then, $0.5 \mathrm{~mL}$ of the homogenate was aseptically transferred into one of the 24 plate wells in which the bacterial capture and other detection procedures were followed based on the protocols described above in section 2.6 .

Eight Salmonella-free chicken samples (confirmed by conventional plating methods) were kindly provided by Shanghai Institute of Quality Inspection and Technical Research (Shanghai, China) and five of them were used as matrix control. The other three chicken samples were also homogenized and washed using $5 \mathrm{~mL}$ of PBS to obtain a turbid suspension. Then $2 \mathrm{~mL}$ of the suspension from each sample was added respectively to three culture flasks containing $30 \mathrm{~mL}$ of nutrient broth. An aliquot of $1 \mathrm{~mL}$ of $S$. pullorum with concentration of approximate $1 \times 10^{2} \mathrm{cfu} \mathrm{mL}^{-1}$ was inoculated in the nutrient broth and the flasks were incubated at $37^{\circ} \mathrm{C}$ with aeration by shaking. Media samples were collected at 1.0, 1.5, 2.0 and $2.5 \mathrm{~h}$, respectively for the detection of the model bacteria. Conventional plating methods were also carried out for the confirmation determination of $S$. pullorum in the chicken from the markets and the artificially inoculated samples.

\section{Results and Discussion}

\section{Electrochemical characteristics of the MWCN-chitosan- peroxidase modified SPE}

A CHI 660C electrochemical working station was applied to investigate the voltammetric behavior of $\mathrm{H}_{2} \mathrm{O}_{2}$ on the MWCN-chitosanperoxidase modified SPEs. Since the detection of S. pullorum was based on the calculation of $\mathrm{H}_{2} \mathrm{O}_{2}$ consumption in this study, it was of great value to set up reliable and sensitive methods to determine $\mathrm{H}_{2} \mathrm{O}_{2}$. We have tried other different methods of the modification of SPEs for the determination of $\mathrm{H}_{2} \mathrm{O}_{2}$ using ferrocene-Nafion-peroxidase, MWCNferrocene-peroxidase and MWCN-Nafion-peroxidase. As expected, the best results were obtained from the MWCN-chitosan-peroxidase modified SPEs, showing ideal stability and sensitivity. In addition, the use of the electron-transfer mediator TMB improved the sensitivity of the voltammetric determination of $\mathrm{H}_{2} \mathrm{O}_{2}$ on the MWCN-chitosanperoxidase modified SPEs (data not shown). To point out, for the determination of $\mathrm{H}_{2} \mathrm{O}_{2}$ with different concentrations, the modified SPE were replaced every time by a new one. Figure 2 showed the differential pulse voltammetric graph of $\mathrm{H}_{2} \mathrm{O}_{2}$ on the MWCN-chitosan-peroxidase modified SPEs using TMB as an electron-transfer mediator. The peak current at the potential of $0.55 \mathrm{~V}$ and was used as the voltammetric signal for the determination of $\mathrm{H}_{2} \mathrm{O}_{2}$. A linear response of the peak current to the concentration of $\mathrm{H}_{2} \mathrm{O}_{2}$ was presented with the regression equation of $y=(6.763 \pm 0.896)+(8.894 \pm 0.973) \times($ correlation coefficient equals to 0.998 , for $\mathrm{n}=6$ ).

Because the detection of $S$. pullorum was performed on the oneoff modified SPE by analyzing the consumption of $\mathrm{H}_{2} \mathrm{O}_{2}$, the stability and reproducibility were key factors affecting the reliability of the amperometric sensor. Fifty repetitive measurements of $100 \mu \mathrm{M} \mathrm{H}_{2} \mathrm{O}_{2}$ were carried out on same day by replacing different one-off SPEs to evaluate the repeatability precision. For the intermediate precision, fifty replicate experiments were performed on each of ten days (five tests per day). The standard deviations for same day and intermediate days were calculated as $4.72 \%$ and $5.13 \%$, respectively. Due to the use of the oneoff SPEs for the determination, the differences of background signals among different SPEs must be considered. When the background noise was subtracted from the peak current for each determination, the standard deviations for same day and intermediate days were reduced to $3.24 \%$ and $4.06 \%$, respectively. Thus the analysis $\mathrm{H}_{2} \mathrm{O}_{2}$ consumption was based on the calculation of the increased current (current signal subtracted by baseline noise) at the potential of $0.55 \mathrm{~V}$. To investigate the stability of the SPEs, fifty of them were stored at $-4^{\circ} \mathrm{C}$ and the determination were conducted for the solutions containing $100 \mu \mathrm{M}$ $\mathrm{H}_{2} \mathrm{O}_{2}$ on the 60 and 120 day, respectively. The results showed that the relative standard deviation (RSD) was $4.62 \%$ and $4.93 \%$, respectively. After six months, the RSD was still less 5.3\%, indicating that the one-off SPEs possessed satisfactory stability.

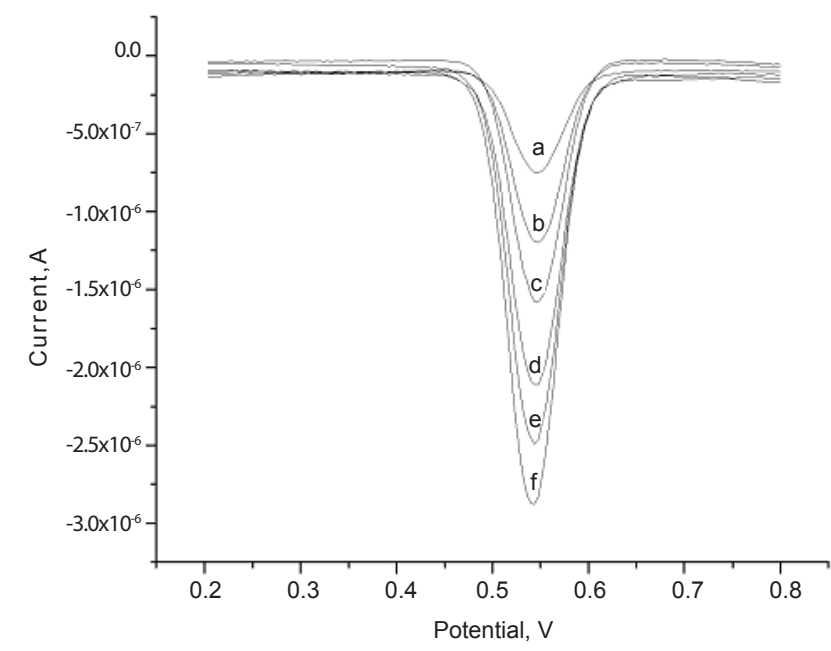

Figure 2: Differential pulse voltammetric graph of $\mathrm{H}_{2} \mathrm{O}_{2}$ on the MWCN-chitosanperoxidase modified SPEs using $20 \mathrm{mM}$ TMB as an electron-transfer mediator. The curves from (a) to (f) were obtained respectively from 10, 50, 100, 150, $200,250 \mu \mathrm{M} \mathrm{H}_{2} \mathrm{O}_{2}$ in the acetate buffer $(0.1 \mathrm{M}, \mathrm{pH} 5.0)$. The parameters set up for differential pulse voltammetry were set as follows: scanning range, 0.2-0.8 $\mathrm{V}$; pulse amplitude, $50 \mathrm{mV}$; pulse duration, $20 \mathrm{~s}$; pulse period, $200 \mathrm{~s}$; scanning speed, $50 \mathrm{mV} \mathrm{s}^{-1}$. 


\section{Optimization of the experimental condition}

Effect of horseradish peroxidase and $\mathrm{H}_{2} \mathrm{O}_{2}$ concentration on sensor response: To investigate the effect of horseradish peroxidase amount on the portable sensor response, the enzymatic solutions containing $0.1,0.3,1.0$ and $3.0 \mathrm{mg} \mathrm{mL}^{-1}$ of horseradish peroxidase were applied during the modification of the SPEs with MWCN-chitosanperoxidase. Amperometric determination was performed on the portable sensor using $100 \mu \mathrm{M} \mathrm{H}_{2} \mathrm{O}_{2}$ as the substrate. To dynamically obtain the electrochemical signals of $\mathrm{H}_{2} \mathrm{O}_{2}$ on the SPEs modified with different amount of horseradish peroxidase, the optical sensor was connected to a computer through part 6 shown in figure 1 and the signals were recorded using current/time $(i-t)$ mode. The effect of HRP amount on the sensor response in time course for determination of $\mathrm{H}_{2} \mathrm{O}_{2}$ was shown in Figure 3. The sensor signals from each solutions with different amounts of HRP were increased rapidly (within 5 seconds) after the addition of $15 \mu \mathrm{L}$ of $100 \mu \mathrm{M} \mathrm{H}_{2} \mathrm{O}_{2}$ solution on the reaction area of the modified SPE. These $i$ - $t$ curves for the detection of $\mathrm{H}_{2} \mathrm{O}_{2}$ on the modified SPE indicated that the sensor response reached peak value and decreased rapidly to plateau phase within $20 \mathrm{~s}$. Thus in this study, $20 \mathrm{~s}$ was selected as the detecting time for the determination of $\mathrm{H}_{2} \mathrm{O}_{2}$ consumption on the portable amperometric sensor. It was clear that more sensitive response would be achieved when relatively higher amount of HRP was applied. However, the sensor signal from the SPEs modified with $3.0 \mathrm{~mL}^{-1}$ of HRP decreased quickly after $5 \mathrm{~s}$, showing the instability for the detection of $\mathrm{H}_{2} \mathrm{O}_{2}$ within $20 \mathrm{~s}$ on the portable amperometric sensor. Thus, $1 \mathrm{~mL}^{-1}$ of HRP solution was chosen during the modification of the SPEs with MWCN-chitosan-peroxidase.

The effect of $\mathrm{H}_{2} \mathrm{O}_{2}$ concentration on the portable sensor response was also investigated and $1 \times 10^{4} \mathrm{cfu} \mathrm{mL}^{-1}$ of $S$. pullorum was applied as the bacterial model. 50,100, 200 and $400 \mu \mathrm{M} \mathrm{H}_{2} \mathrm{O}_{2}$ solutions were mixed respectively with the model bacteria and the detection signal were recorded on the sensor after the accomplishment of the catalasecatalyzed reaction step. The results showed that the $\mathrm{H}_{2} \mathrm{O}_{2}$ solution with relatively lower concentration of $50 \mu \mathrm{M}$ displayed the instability for the detection of the bacteria in this sensing system. The deflection of $28 \pm$

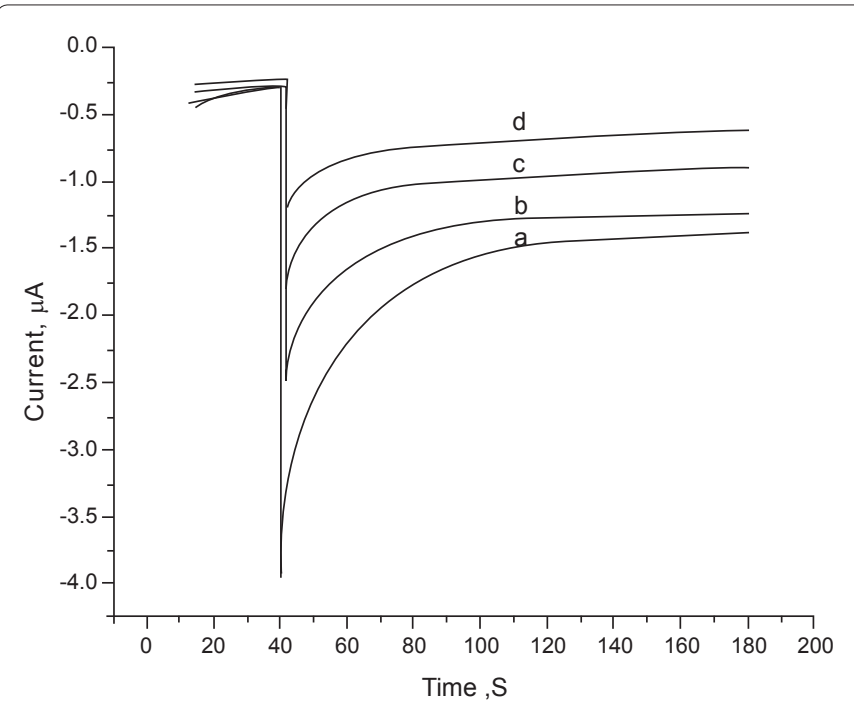

Figure 3: Effect of the HRP concentrations on the response of the portable amperometric sensor to $\mathrm{H}_{2} \mathrm{O}_{2}$ in time course. From curve (a) to curve (d), the concentration of HPR for the modification of SPEs was 3.0,1.0, 0.3 and $0.1 \mathrm{mg}$ $\mathrm{mL}^{-1}$, respectively.

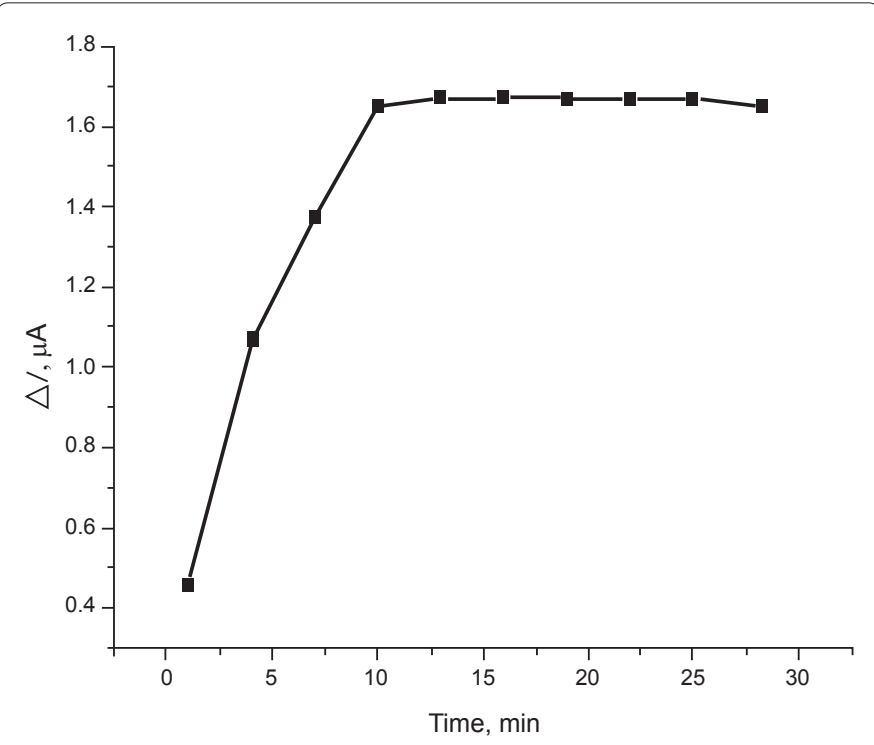

Figure 4: Effect of the incubation time on the portable amperometric sensor signal. $1 \times 10^{4} \mathrm{cfu} \mathrm{mL}^{-1}$ of $S$. pullorum was used and the change of the current was recorded as the sensor signal.

$4 \%$ was obtained from $100 \mu \mathrm{M} \mathrm{H}_{2} \mathrm{O}_{2}$ whereas the results from 50,200 and $400 \mu \mathrm{M} \mathrm{H}_{2} \mathrm{O}_{2}$ showed the deflection of $43 \pm 7 \%$, $36 \pm 6 \%$ and 45 $\pm 7 \%$, respectively. We selected $100 \mu \mathrm{M} \mathrm{H}_{2} \mathrm{O}_{2}$ for all the determination in this study considering the data described above and the fact that the relatively lower concentration of $\mathrm{H}_{2} \mathrm{O}_{2}$ was helpful to improve the sensitivity since the detection of $S$. pullorum (a catalase-positive microorganism) was based on the detection of $\mathrm{H}_{2} \mathrm{O}_{2}$ consumption.

Influence of the incubation time on the amperometric sensor signal: Since the detection of $\mathrm{H}_{2} \mathrm{O}_{2}$ consumption on the portable amperometric sensor took only $20 \mathrm{~s}$, the testing time of this analytical technique was mainly spent at the incubation step where $\mathrm{H}_{2} \mathrm{O}_{2}$ was subjected to dismutation reaction catalyzed by the catalase from $\mathrm{S}$. pullorum. To further investigate the influence of the incubation time on the amperometric sensor signal, $15 \mu \mathrm{L}$ of the mixture of the dismutation reaction product was collected at an interval of $3 \mathrm{~min} .1 \times 10^{4} \mathrm{cfu} \mathrm{mL}^{-1}$ of $S$. pullorum was used as the bacterial model. The change of the current was recorded as the sensor signals. Figure 4 showed the sensor response to the incubation time, indicating that the response increased very quickly within $8 \mathrm{~min}$, but after $8 \mathrm{~min}$ the change of the current reached plateau phase and even slightly decreased after $20 \mathrm{~min}$. Thus 8 min was used as the optimized incubation time for the determination of $S$. pullorum in this analyzing system.

Effect of pH: It was obvious that two separate reactions catalyzed respectively by catalase and HRP were involved in this analytic technique using the portable amperometric sensor based on the MWCN-chitosan-peroxidase modified SPEs. In order to study the effect of $\mathrm{pH}$ on the activities of $\mathrm{HRP}, 15 \mu \mathrm{L}$ of $100 \mu \mathrm{M} \mathrm{H}_{2} \mathrm{O}_{2}$ solutions with different $\mathrm{pH}$ values in a range from 3.0 to 9.0 was added to the reaction area of the modified SPEs and the sensor responses were recorded using current/time mode. It was found that optimum sensor response was achieved at $\mathrm{pH} 5.0$ though no significant response was observed in the 4.0-7.0 of $\mathrm{pH}$ value, suggesting that weak acid environment was more suitable for the HRP catalyzed reaction. Although the detection of the $\mathrm{H}_{2} \mathrm{O}_{2}$ consumption was performed on the one-off modified SPEs, the $\mathrm{pH}$ value of the solution in the plate wells was the main concern 


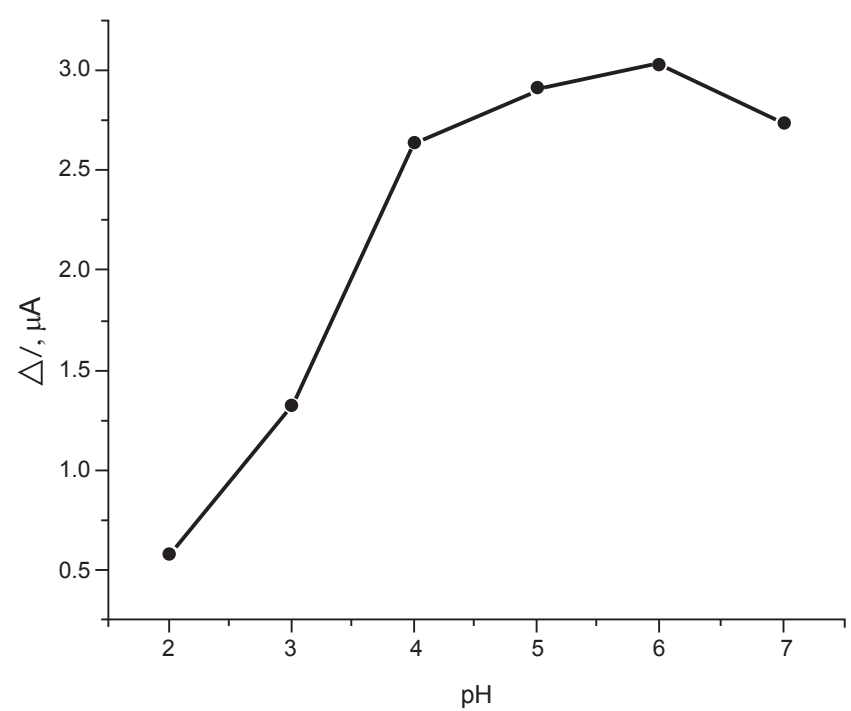

Figure 5: Effect of $\mathrm{pH}$ on the response of the portable amperometric sensor.

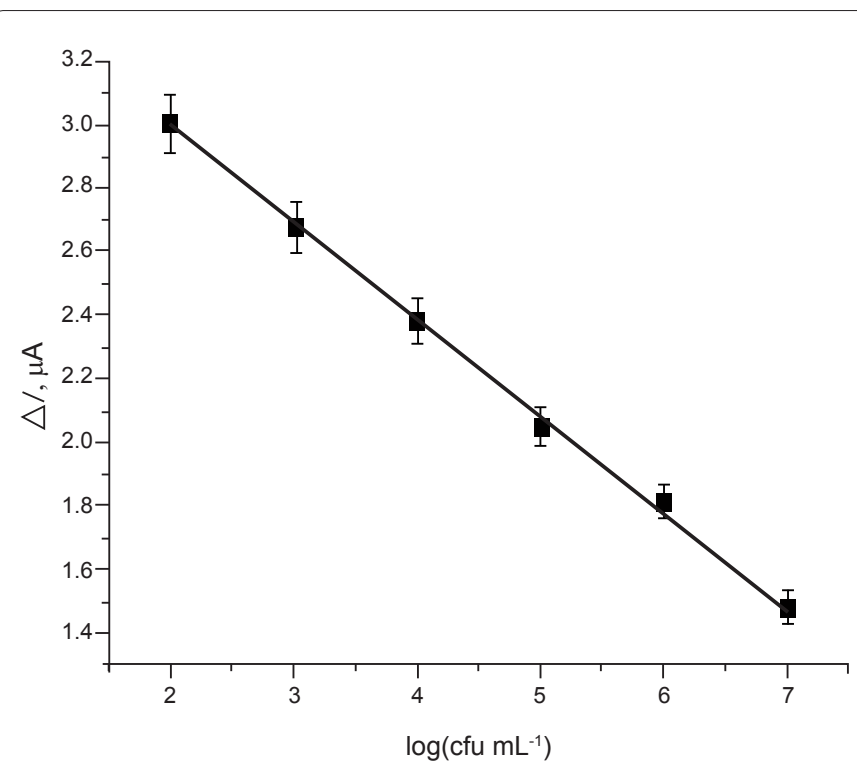

Figure 6: Calibration plot for the determination of $S$. pullorum on the amperometric sensor based on the MWCN-Nafion-peroxidase modified SPEs.

affecting the activities of both HRP and catalase since the supporting electrolytes added on the one-off modified SPEs were obtained from the mixture of the bacterial sample and acetate buffer. With the purpose of investigating the effect of $\mathrm{pH}$ on the sensor response, prior to the incubation step, the $\mathrm{pH}$ value of the mixture (equal volume of bacterial sample and $0.1 \mathrm{M}$ acetate buffer containing $100 \mu \mathrm{L}$ of $\mathrm{H}_{2} \mathrm{O}_{2}$ ) was adjusted from 2.0 to 7.0. The sensor responses for the mixtures with different $\mathrm{pH}$ values were recorded by the methods described above. It was observed that no significant change in sensor response was obtained in the 4.08.0 range of $\mathrm{pH}$ values. However, a maximum response was achieved at $\mathrm{pH} 6.0$ (Figure 5). Therefore, a $\mathrm{pH}$ value of 6.0 was selected for the determination of $S$. pullorum in this analytical technique.

\section{Calibration curves for the determination of S. pullorum}

In order to establish the calibration curves for the determination of S. pullorum, serial dilutions of the bacteria were prepared and the current changes were recorded for each dilution sample in a triplicate way under the optimized conditions described above compared with a negative control solution (nutrient broth). It was found that sensor signal decreased linearly with the logarithm value of $S$. pullorum concentration in the range from $1.75 \times 10^{2} \mathrm{cfu} \mathrm{mL}^{-1}$ to $2.63 \times 10^{7} \mathrm{cfu} \mathrm{mL}^{-1}$ (Figure 6). The calibration curves could be represented by the linear regression equation $\mathrm{y}=(3.763 \pm 0.652)-(0.299 \pm 0.0537) \log (\mathrm{C}, \mathrm{cfu}$ $\mathrm{mL}^{-1}$ ) (correlation coefficient equals to 0.998 , for $\mathrm{n}=6$ ). The detection limit was calculated as the bacterial concentration which produced an analytical signal (current change) three times the background noise. This technique allowed the quantification of S. pullorum in culture media with the detection limit of $100 \mathrm{cfu}$ within $10 \mathrm{~min}$.

Due to the bacterial proliferation in culture media and food samples, the evaluation of the microorganism contamination at different time is of great value. To monitor the bacterial growth in the culture media using the amperometric sensor and investigate the reliability of the portable amperometric sensor, the determinations of $S$. pullorum at different time (1, 2, 4, 6, 8, 10, 12 and $24 \mathrm{~h})$ were carried out under the optimized conditions described above. The results showed that the current change decreased linearly with the logarithm value of the total count of the bacteria confirmed by the conventional plating methods. The linear regression equation was represented by $\mathrm{y}=(3.539 \pm$ $0.848)-(0.393 \pm 0.0726) \log \left(\mathrm{C}, \mathrm{cfu} \mathrm{mL}^{-1}\right)$ (correlation coefficient equals to 0.996 , for $\mathrm{n}=8$ ).

\section{Determination of $S$. pullorum in chicken samples}

The safety of the chicken sold in free market is still a public concern due to the lack of efficient monitoring and quality control system. Therefore, rapid technique for the evaluation of bacterial contamination in food samples is very necessary. To investigate the dependability of the portable amperometric sensor for monitoring $S$. pullorum contamination in food, thirty chicken samples collected from the free markets were used and subjected directly to the detection of S. pullorum on the portable amperometric sensor under the optimized methods described in Section 3. The results indicated that S. pullorum was detected in three out of the thirty chicken samples without bacterial enrichment. The total count of the S. pullorum in the three samples was $1.7 \times 10^{3}, 5.3 \times 10^{2}$ and $2.6 \times 10^{4} \mathrm{cfu} \mathrm{mL}^{-1}$, respectively. To study the effect of the bacterial enrichment time on the detection of $S$. pullorum in chicken samples and compare the consistence of this technique with the conventional methods, three $S$. pullorum-free chicken samples were inoculated with the model bacteria and the detection was performed on the sensor at 1.0, 1.5, 2.0 and $2.5 \mathrm{~h}$, respectively. Conventional plating methods were also conducted for the same samples. Table 1 demonstrated the results from the portable amperometric sensor and the conventional methods, indicating the satisfactory consistency between these two techniques. It was obvious that the bacterial sample with initial concentration of $60-100 \mathrm{cfu}^{\mathrm{mL}^{-1}}$ would be detected after 1.5-2 h of enumeration. Therefore, with the combination of the sensing system and bacterial enrichment, the detection limit would be decreased to $60 \mathrm{cfu} \mathrm{mL}^{-1}$, demonstrating the favorable sensitivity.

\section{Conclusion}

In this experiment, a portable amperometric sensor was established for the rapid evaluation of Salmonella pullorum contamination in chicken samples. The specificity of this technique was based on the 


\begin{tabular}{|c|c|c|c|}
\hline \multirow[t]{2}{*}{ Samples } & \multirow[t]{2}{*}{$\begin{array}{l}\text { Incubation } \\
\text { time (h) }\end{array}$} & \multicolumn{2}{|c|}{$\begin{array}{c}\text { Number of S. Pullorum detected, log } \\
\left.\text { (C, cfu mL } \mathrm{mL}^{-1}\right)\end{array}$} \\
\hline & & $\begin{array}{c}\text { Amperometric sensor } \\
\text { methods }\end{array}$ & Conventional methods \\
\hline \multirow{4}{*}{ S1 } & 1.0 & $-\mathrm{a}^{\mathrm{a}}$ & $1.82 \pm 0.37$ \\
\hline & 1.5 & $3.13 \pm 0.56$ & $3.42 \pm 0.28$ \\
\hline & 2.0 & $3.55 \pm 0.49$ & $3.67 \pm 0.31$ \\
\hline & 2.5 & $4.15 \pm 0.52$ & $4.46 \pm 0.46$ \\
\hline \multirow{4}{*}{$\mathrm{S} 2$} & 1.0 & $1.90 \pm 0.71$ & $2.15 \pm 0.43$ \\
\hline & 1.5 & $2.97 \pm 0.63$ & $3.13 \pm 0.52$ \\
\hline & 2.0 & $3.28 \pm 0.65$ & $3.85 \pm 0.62$ \\
\hline & 2.5 & $3.96 \pm 0.46$ & $4.23 \pm 0.74$ \\
\hline \multirow{4}{*}{ S3 } & 1.0 & $2.12 \pm 0.56$ & $2.37 \pm 0.49$ \\
\hline & 1.5 & $3.05 \pm 0.37$ & $2.96 \pm 0.52$ \\
\hline & 2.0 & $3.78 \pm 0.41$ & $3.52 \pm 0.57$ \\
\hline & 2.5 & $4.15 \pm 0.53$ & $3.97 \pm 0.62$ \\
\hline
\end{tabular}

aNot detectable.

Table 1: Comparison of the amperometric sensor with the conventional method for the detection of S. Pullorum.

capture of the target bacteria on the cellulose nitrate membrane through specific polyclonal antibodies. Due to the use of the MWCN-chitosanperoxidase modified SPEs, this sensing system showed favorable sensitivity, allowing the quantification of $S$. pullorum in culture media with the detection limit of $100 \mathrm{cfu} \mathrm{mL}^{-1}$ within $10 \mathrm{~min}$ for each sample, without bacterial enumeration. The stability, reproducibility and sensitivity of the modified SPE were reliable for the determination of hydrogen peroxide consumption. In addition, the determination of $S$. pullorum was easily carried out by adding the reaction product, which was obtained from the hydrogen peroxide dismutation catalyzed by the bacterial catalase, to the reaction area of the modified SPEs. Successive analysis was conveniently conducted by replacing the modified SPE with a new one. By the combination of the portable sensing system and bacterial enumeration, the detection limit could be decreased to $60 \mathrm{cfu}$ $\mathrm{mL}^{-1}$ within two hours. Furthermore, no labeled secondary antibody was applied, shortcutting the analyzing procedures compared with conventional immunoassays. In summary, this portable sensing system is a rapid, cost-effective and straight-forward approach for monitoring S. pullorum contamination in food samples.

\section{Acknowledgements}

Financial support from the Shanghai Science Committee (Project 06DZ05825 for Shanghai 2010 Expo) is greatly acknowledged. The authors also thank Dr. Jinqi Yuan for technical support for the design and fabrication of the portable amperometric sensor.

\section{Biographies}

Dr. Guoyan Liu obtained her first degree in veterinary medicine at Zhelimu Husbandry College (Inner Mongolia, P.R. China) in 1994 and her Ph.D. in the field of fast microorganism detection in 2000 at the Department of Veterinary Medicine, Northeast Agriculture University (Heilongjiang Province, P.R. China). She is a staff of Food Safety \& Biosensor Lab (Shanghai Jiaotong University) established in 2002. Her main areas of research include the fabrication and development of novel techniques for fast detection of hazardous substance in animal feeds and products based on biosensor, molecularly imprinted polymers, immunoassay and voltammetric determination.

Dr. Chunyan Chai obtained his first degree in veterinary medicine at Gansu Agriculture University (Gansu Province, P.R. China) in 1994 and his Ph.D. in the field of fast microorganism detection in 2000 at the Department of Veterinary Medicine, Northeast Agriculture University (Heilongjiang Province, P.R. China). He is the leader of the Biosensor Lab in School of Agriculture and Biology, Shanghai Jiaotong University (Shanghai, P.R. China). His main areas of research include microorganism detection, biosensors and novel sensor materials for commercial applications

Miss Bing Yao obtained her bachelor degree in agriculture at School of Food Science, Nanjing Agriculture University (Jiangsu Province, P.R. China) in the field

of food safety control in 2007. She is a postgraduate in the Food Safety \& Biosenso Lab. Her main areas of research include the fabrication and development of nove techniques for fast detection of catalase-positive microorganism in food sample.

\section{References}

1. Sinell HJ (1995) Control of food-borne infections and intoxications. Int J Food Microbiol 25: 209-217.

2. Henson S (1997) Estimating the incidence of food-borne Salmonella and the effectiveness of alternative control measures using the Delphi method. Int $J$ Food Microbiol 35: 195-204.

3. Newell DG, Koopmans M, Verhoef L, Duizer E, Aidara-Kane A, et al. (2010) Food-borne diseases-the challenges of 20 years ago still persist while new ones continue to emerge. Int J Food Microbiol 139: S3-S15.

4. O'Connor AM, Denagamage T, Sargeant JM, Rajić A, McKean J (2008) Feeding management practices and feed characteristics associated with Salmonella prevalence in live and slaughtered market-weight finisher swine: A systematic review and summation of evidence from 1950 to 2005. Prev Vet Med 87: 213228.

5. Rhoades JR, Duffy G, Koutsoumanis K (2009) Prevalence and concentration of verocytotoxigenic Escherichia coli, Salmonella enterica and Listeria monocytogenes in the beef production chain: A review. Food Microbiol 26: 357 376 .

6. Dunkley KD, Callaway TR, Chalova VI, McReynolds JL, Hume ME, et al. (2009) Foodborne Salmonella ecology in the avian gastrointestinal tract. Anaerobe 15 26-35.

7. Yang L, Li Y, Griffis CL, Johnson MG (2004) Interdigitated microelectrode (IME) impedance sensor for the detection of viable Salmonella typhimurium. Biosens Bioelectron 19: 1139-1147

8. Das RD, RoyChaudhuri C, Maji S, Das S, Saha H (2009) Macroporous silicon based simple and efficient trapping platform for electrical detection of Salmonella typhimurium pathogens. Biosens Bioelectron 24: 3215-3222.

9. Li S, Li Y, Chen H, Horikawa S, Shen W, et al. (2010) Direct detection of Salmonella typhimurium on fresh produce using phage-based magnetoelastic biosensors. Biosens Bioelectron 26: 1313-1319.

10. Siripatrawan U, Harte BR (2007) Solid phase microextraction/gas chromatography/mass spectrometry integrated with chemometrics for detection of Salmonella typhimurium contamination in a packaged fresh vegetable. Anal Chim Acta 581: 63-70.

11. Huang S, Yang H, Lakshmanan RS, Johnson ML, Wan J, et al. (2009) Sequential detection of Salmonella typhimurium and Bacillus anthracis spores using magnetoelastic biosensors, Biosens Bioelectron 24: 1730-1736.

12. Ruan C, Yang L, Li Y (2002) Rapid detection of viable Salmonella typhimurium in a selective medium by monitoring oxygen consumption with electrochemical cyclic voltammetry. J Electroanal Chem 519: 33-38.

13. Siripatrawan U, Linz JE, Harte BR (2006) Electronic sensor array coupled with artificial neural network for detection of Salmonella typhimurium. Sens Actuators B: Chem 119: 64-69.

14. Kim J, Demeke T, Clear RM, Patrick SK (2006) Simultaneous detection by PCR of Escherichia coli, Listeria monocytogenes and Salmonella typhimurium in artificially inoculated wheat grain. Int J Food Microbiol 111: 21-25.

15. Gehring AG, Crawford CG, Mazenko RS, Van Houten LJ, Brewster JD (1996) Enzyme-linked immunomagnetic electrochemical detection of Salmonella typhimurium. J Immunol Methods 195: 15-25.

16. Kang MS, Kwon YK, Jung BY, Kim A, Lee KM, et al. (2011) Differential identification of Salmonella enterica subsp. enterica serovar Gallinarum biovars Gallinarum and pullorum based on polymorphic regions of glgC and speC genes. Vet Microbiol 147: 181-185.

17. Shah DH, Park JH, Cho MR, Kim MC, Chae JS (2005) Allele-specific PCR method based on rfbS sequence for distinguishing Salmonella gallinarum from Salmonella pullorum: serotype-specific rfbS sequence polymorphism. J Microbiol Methods 60: 169-177

18. Brooks BW, Perry MB, Lutze-Wallace CL, MacLean LL (2008) Structura characterization and serological specificities of lipopolysaccharides from Salmonella enterica serovar Gallinarum biovar pullorum standard, intermediate and variant antigenic type strains. Vet Microbiol 126: 334-344. 
Citation: Liu G, Chai C, Yao B (2013) Rapid Evaluation of Salmonella pullorum Contamination in Chicken Based on a Portable Amperometric Sensor. J Biosens Bioelectron 4: 137. doi:10.4172/2155-6210.1000137

19. Liu Y, Che Y, Li Y (2001) Rapid detection of Salmonella typhimurium using immunomagnetic separation and immuno-optical sensing method. Sens Actuators B: Chem 72: 214-218.

20. Sunil D, Saroj R, Shashidhar, Karani M, Bandekar JR (2008) Rapid, sensitive, and validated method for detection of Salmonella in food by an enrichment broth culture- Nested PCR combination assay. Mol Cell Probes 22: 201-206.

21. Whyte P, Mc Gill K, Collins JD, Gormley E (2002) The prevalence and PCR detection of Salmonella contamination in raw poultry. Vet Microbiol 89: 53-60.

22. Oliveira SD, Santos LR, Schuch DMT, Silva AB, Salle CTP, et al. (2002) Detection and identification of Salmonellas from poultry-related samples by PCR. Vet Microbiol 87: 25-35.

23. Malorny B, Bunge C, Helmuth R (2007) A real-time PCR for the detection of Salmonella Enteritidis in poultry meat and consumption eggs. J Microbio Methods 70: 245-251.

24. Pusterla N, Byrne BA, Hodzic E, Mapes S, Jang SS, et al. (2010) Use of quantitative real-time PCR for the detection of Salmonella spp. in fecal samples from horses at a veterinary teaching hospital. Vet J 186: 252-255.

25. Wang H, Blais BW, Brooks BW, Yamazaki H (1996) Salmonella detection by the polymyxin-cloth enzyme immunoassay using polyclonal and monoclonal detector antibodies. Int J Food Microbiol 29: 31-40.

26. Hoszowski A, Fraser AD, Brooks BW, Riche EM (1996) Rapid detection and enumeration of Salmonella in chicken carcass rinses using filtration, enrichment and colony blot immunoassay. Int J Food Microbiol 28: 341-350.

27. Leon-Velarde CG, Zosherafatein L, Odumeru JA (2009) Application of an automated immunomagnetic separation-enzyme imunoassay for the detection of Salmonella enterica subspecies enterica from poultry environmental swabs. J Microbiol Methods 79: 13-17.

28. Cudjoe KS, Hagtvedt T, Dainty R (1995) Immunomagnetic separation of Salmonella from foods and their detection using immunomagnetic particle (IMP)-ELISA. Int J Food Microbiol 27: 11-25.

29. Wang J, Mark Ensor C, Dubuc GJ, Narang SA, Daunert S (2001) Genetically fused single-chain anti-Salmonella antibody with aequorin: a bioluminescence immunoassay for a Salmonella antigen. Anal Chim Acta 435: 255-263.
30. Qiu J, Zhou Y, Chen H, Lin JM (2009) Immunomagnetic separation and rapid detection of bacteria using bioluminescence and micro fluidics. Talanta 79: 787795.

31. Nandakumar V, La Belle JT, Reed J, Shah M, Cochran D, et al. (2008) A methodology for rapid detection of Salmonella typhimurium using label-free electrochemical impedance spectroscopy. Biosens Bioelectron 24: 1045-1048.

32. Yang $L$ (2008) Electrical impedance spectroscopy for detection of bacterial cells in suspensions using interdigitated microelectrodes. Talanta 74: 16211629 .

33. Yang L, Bashir R (2008) Electrical/electrochemical impedance for rapid detection of foodborne pathogenic bacteria. Biotechnol Adv 26: 135-150.

34. Si SH, Li X, Fung YS, Zhu DR (2001) Rapid detection of Salmonella enteritidis by piezoelectric immunosensor. Microchem J 68: 21-27.

35. Kim GH, Rand AG, Letcher SV (2003) Impedance characterization of a piezoelectric immunosensor part II: Salmonella typhimurium detection using magnetic enhancement. Biosens Bioelectron 18: 91-99.

36. Zhou C, Pivarnik P, Auger S, Rand A, Letcher S (1997) A compact fiber-optic immunosensor for Salmonella based on evanescent wave excitation. Sens Actuators B: Chem 42: 169-175.

37. Kim N, Park IS, Kim WY (2007) Salmonella detection with a direct-binding optical grating coupler immunosensor. Sens Actuators B: Chem 121: 606-615.

38. Ko S, Grant SA (2006) A novel FRET-based optical fiber biosensor for rapid detection of Salmonella typhimurium. Biosens Bioelectron 21: 1283-1290.

39. Ivnitski D, Abdel-Hamid I, Atanasov P, Wilkins E (1999) Biosensors for detection of pathogenic bacteria. Biosens Bioelectron 14: 599-624.

40. Salam F, Tothill IE (2009) Detection of Salmonella typhimurium using an electrochemical immunosensor. Biosens Bioelectron 24: 2630-2636.

41. Liébana S, Lermo A, Campoy S, Cortés MP, Alegret S, et al. (2009) Rapid detection of Salmonella in milk by electrochemical magneto-immunosensing Biosens Bioelectron 25: 510-513.

42. Yang L, Li Y (2006) Detection of viable Salmonella using microelectrodebased capacitance measurement coupled with immunomagnetic separation. J Microbiol Methods 64: 9-16. 